\title{
CUCUZZA, Héctor Rubén (Dir.); SPREGELBURD, Roberta Paula (Codir.). Historia de la lectura en la Argentina: del catecismo colonial a las netbooks estatales. Buenos Aires: Editoras del Calderón, 2012. $680 \mathrm{p}$.
}

\author{
Diane Valdez ${ }^{*}$
}

Lanzado en el año 2012, el libro que ahora reseño es una producción de investigación del equipo de Historia Social de La Educación y del Grupo HISTELEA - Historia Social de la Enseñanza de la Lectura y la Escritura en Argentina da Universidad Nacional de Luján, sita en la provincia de Buenos Aires, Argentina. Cucuzza y Spregelburd, reunieron dieciséis textos sobre la lectura en distintos períodos históricos, escritos por autores del área de historia, historia de la educación, didáctica, análisis del discurso y lingüística. En el primer capítulo es realizada una revisión teórica a partir de la historia social de la educación y de la escolarización de la cultura que, de acuerdo con los autores, facilita la descripción de la compleja institucionalización de la producción, transmisión y apropiación de los saberes. Por medio de la enseñanza de la lectura, la obra remite al lector a las formas en que el proceso de escolarización se configuró en la Argentina. En el segundo capítulo Leer y rezar en la Buenos Aires aldeana, Cucuzza discurre a respecto de la lectura y el aprendizaje en el espacio urbano en el periodo colonial, cuando la lectura y la escritura estaban limitadas a la aristocracia blanca, española o criolla. El aprendizaje de la lectura se hacía por el método de repetición y memorización por medio de cartillas, silabarios y cartas, los pocos libros de lectura en serie eran catecismos cristianos y patrióticos, ambos servían para divulgar la palabra divina, la razón iluminista y la palabra del soberano, para formar un niño en la triada cortesía, urbanidad y civilización.

En el tercer capítulo Leer, escribir, votar: la conflictiva definición del currículum ciudadano, Bottarini explica la propuesta del Congreso Pedagógico de 1882 de limitar el voto a los ciudadanos alfabetizados, discute la compleja relación entre alfabetización y capacidad electoral como parte de los dispositivos que construyeran la categoría de ciudadano. Discurre al respecto del papel de la alfabetización como requisito para producir sujetos con derechos políticos como algo propio del siglo XX, en cual se substituye el ideal de "súbdito fiel" por el del "ciudadano activo", la escuela era un espacio de estos nuevos principios,

\footnotetext{
*Professora da Faculdade de Educação da Universidade Federal de Goiás. E-mail: <dvaldez@fe.ufg.br>
} 
donde la lectura y la escritura son más una obligación que un derecho. En el capítulo cuatro Escenas de lectura escolar: la intervención normalista en la formación de la cultura letrada moderna, De Miguel analiza las escenas de lectura escolar y los aspectos performativo, pedagógico, alumno lector, control de la alfabetización y funciones de la lectura en el horizonte cultural letrado. Analiza autobiografía, documentos oficiales y un libro de lectura, reforzando que tales escenas tuvieron influencia en la historia de la enseñanza de la lectura en el país, pues en el imaginario pedagógico se atribuía a la lectura una inmediata fuerza civilizatoria en la Argentina moderna.

Spregelburd, en el capítulo cinco ¿Qué se puede leer en la escuela? El control estatal del texto escolar (1880-1916), evalúa el sistema educativo nacional de la segunda mitad del siglo XIX, debatiendo acerca de las diversas formas de control, sea en la producción del texto, circulación, interpretación y otras variaciones complejas. La creencia en la lectura como canal de civilización y moralización, parte del ideario de la élite liberal, creó nuevos mecanismos para la educación de los lectores y la promoción de la lectura, la escolarización primaria fue prioridad en la política de consolidación del Estado nacional y estableció mecanismos legales para seleccionar libros escolares. Entre los varios criterios se hacía presente en las obras la enseñaza cívica, que debería someter al niño a la obediencia de las leyes, habituándolo desde temprano a respetar sus disposiciones. En el capítulo seis Nacimiento y trayectoria de una nueva generación de libros de lectura escolar: 'El Nene' (1895-1956), Linares eligió como objeto de estudio este libro debido a la innovación de contenidos y por haber sido adoptado durante seis décadas. Delante del desafío de legitimar la formación de identidades en una incipiente nación, los libros de lectura sufrían críticas de inadecuación y ausencia de contenidos nacionales. La obra analizada fue el primer libro de lectura auténticamente nacional, innovaciones como la edición, metodología, imagen y otros servirán de referencia para la producción de otros libros de lectura. Linares analiza las relaciones de clase, género y racial, la palabra como partida para la alfabetización, la imagen como soporte, temáticas nacionales, la relación con la oralidad, la influencia religiosa, la materialidad, las alteraciones hechas en las ediciones, el lector ampliado y otros temas que buscaban la conformación del ciudadano urbano y moderno.

En el séptimo capítulo, De los Apeninos a los Andes: la lectura de Corazón en la escuela argentina, Spregelburd discurre al respecto de la incorporación, de la prohibición y de la propuesta de argentinización de la obra Corazón (1886) del italiano Edmundo De Amicis. La obra, que retrata modelos y concepciones de la sociedad italiana, fue ampliamente aceptada por pedagogos de distintas escuelas teóricas en la primera mitad del siglo XX. Mientras fue objeto de cuestionamiento de orden pedagógica y política, fue prohibida su circulación en 
1910 por el Estado con el argumento de que representaba peligro por atentar contra la formación de la nacionalidad. Se publican versiones nacionalizadas de la obra, reescrituras que incluían temas nacionalizados, manteniendo fielmente el contenido moralizante y la armonía entre las clases sociales de la obra italiana. En el octavo capítulo ¿Para qué enseñar a leer? Cultura política y prácticas escolares de lectura en el período de entreguerras, Pineau pondera al respecto de la enseñaza de la lectura y de la escritura en la década del treinta en la Argentina, analizando las distintas articulaciones políticas, sociales y culturales. La escuela argentina tenía por objetivo disciplinar e integrar las clases populares privilegiando el sujeto pedagógico, pero episodios universales, guerra, revolución, crisis, etc., sacudirán y exigirán nuevas articulaciones en los registros pedagógicos. Importantes mudanzas, como la difusión de los medios agitaban la cultura local, la escuela necesitaba adecuarse a los nuevos tiempos, la asociación entre escuela y progreso permanecía, así como la creencia en la articulación entre cultura política y sistema educativo, mientras la matriz escolar estaba desgastada. La lucha contra el analfabetismo continuaba, y aún surge una nueva amenaza de subversión cultural, los semianalfabetos. Los años treinta, (50 años del sistema educativo), fueron un período rico permeado por diagnósticos, debates, propuestas, que indicaban mudanzas por medio de escuelas diferenciadas, vigilancia metódica (delación), políticas coercitivas de represión al analfabetismo, campañas, conferencias, etc. Pienau resalta que el viejo modelo de lectura, considerado agotado, fue substituido por nuevos dispositivos, con criterios que combinaban nacionalismo y, a veces, la religión católica, proponían una nueva homogeneización ideológica de la población.

En la parte nueve Textos y lecturas escolares durante el primer peronismo: Evita también fue palabra generadora, Colotta, Cucuzza y Rodríguez, revelan, por medio de los libros escolares, como si expresaran las disputas políticas en los primeros gobiernos peronistas (1946-1955). Las luchas de poder entre las políticas hegemónicas y contrahegemónicas en la historia de la educación argentina se reflejaron en cambios en las obras escolares. La tentativa de imponer una ley que estableciera la adopción de un libro único para las escuelas, provocó fuertes reacciones de la oposición y de las editoriales. Aún delante del fracaso de la ley, las obras editadas a partir de 1951 dedicaron un número expresivo de símbolos, textos e imágenes que hacían apología de Perón y Eva Perón. Con cualidades para ser imitadas se exaltaba en diferentes espacios la intervención personal del presidente y Eva Perón era asociada al trabajo social con niños, mujeres, ancianos, etc., construyendo, en el imaginario colectivo, una imagen mitificada, santificada de la primera dama, sobretodo después de su muerte con la imposición de su obra La razón de mi vida distribuída gratuitamente como libro de lectura obligatorio, a pesar de las críticas de improcedencia política. Los autores apuntan que las lecturas reiterativas y persuasivas enfatizaban la imagen 
del peronismo con algunos elementos nuevos, como la dignificación del trabajo manual, incorporación del pueblo, aunque en condición subordinada, como protagonistas, etc.

En el décimo capítulo Escenas de lectura en el contexto de expansión de la cultura escrita en la segunda mitad del siglo XX, Spregelburd aborda las escenas de lectura de los libros, sus prescripciones y prácticas sociales extraescolares en los años 1955 a 1976, período de expansión de la cultura escrita. La autora indaga en qué medida las prácticas lectoras se corresponden con la práctica social del momento histórico; para esta tarea distinguió tres grupos de obras; las producidas con anterioridad al peronismo (que circulaban en el período); a partir de 1955 (sin alteraciones substanciales); y las que innovaran (estructura modificada). Después de analizar las obras la autora observó diferentes aspectos y percibió que algunas lecturas se mantienen descontextualizadas, prevaleciendo la omisión de las transformaciones demográficas, sociales, económicas y culturales de los períodos analizados. Mientras que fragmentadas y distorcionadas, las representaciones también no están a la margen de los cambios apuntados fuera del espacio escolar.

Linares, en el capítulo once La homogenización de los libros: Reglamento del Concurso, Estudio y Aprobación de textos, 1941, trata al respecto del Reglamento que homogeneizó las producciones de los libros de lectura en las tres décadas siguientes substituyendo contenidos enciclopédicos e instructivos por aspectos formativos y consagrando el método de la palabra generadora para la enseñaza de la lectura. Permanecerán temáticas anteriores, entretanto las mudanzas políticas (sindicalismo, huelga etc.) generan mayor control de los libros de lectura, la corriente espiritualista nacionalista y autoritaria con valores católicos se sobrepone a la laicidad, se incorpora el militarismo en el espacio escolar, se valoriza la historia de la corriente positivista y los contenidos literarios 'realistas', inserta el método de la palabra generadora. Predominan las criticas al Reglamento enfatizando las condiciones materiales, limitación de las obras y la prescripción de actividades al final de las lecturas. En el capítulo doce, Artiega, Historias indigenas de acceso a la lectura y escrita en tres ámbitos: Religión, familia, escuela (C.1914-1960) presenta resultados de un estudio sobre la lectura y la escritura entre los miembros del pueblo wichí en la Misión del Chaco, primera misión anglicana establecida en Salta (1914) y el contraste de estas prácticas con el ingreso del contexto estatal de la escuela pública en 1950. La autora aborda la llegada de los protestantes anglicanos en la región y su proyecto evangélico en el Chaco y Formosa, local marcado por relaciones interétnicas conflictivas entre militares, policías y criollos y los indígenas, que miraban la misión como una especie de refugio delante de los conflictos. Los anglicanos, vinculados a la industria azucarera, de forma contradictoria y ambigua, intentaban por medio del disciplinamiento social, educación, salud, trabajo y evangelización, integrar 
a los indios en los órdenes religioso, étnica y nacional. Los primeros contactos con la lectura se hacían por medio de la Biblia, traducida al wichí (lengua de los nativos). La experiencia fue un marco de relación de poder, por medio del alfabeto y de la imprenta, los anglicanos promoverán así la desestructuración de la cultura originaria.

En el capítulo trece Alfabetización de adultos y sujetos políticos (C.1960-1970), Bottarini debate acerca de la propuesta de construcción de la subjetividad política gubernamental de alfabetización de adultos en los años sesenta y setenta. Cambia la perspectiva de "civilización y barbarie" en la cual el adulto analfabeto representaba la negatividad a la formación de la civilización. El analfabeto era concebido con especificidades psicológicas diferentes de la infancia, por tanto se prescribía a los educadores la necesidad de inculcar conocimientos de forma mecanicista, instrumental y práctica, ignorando la subjetividad y la capacidad simbólica de estos sujetos. Considerando que el analfabetismo incitaba ideas extremistas y disolventes justificó la participación logística del ejército, en todo el país, en la campaña de alfabetización. El adulto analfabeto es construido bajo el prisma de bárbaro, peligroso, manipulable, improductivo, subdesarrollado, incapaz de ejercer sus derechos. Se crea la Dirección Nacional de Educación de Adultos (DINEA), ligada al catolicismo, así el analfabeto es visto como "pecador", el concepto es relacionado con el concepto de servidumbre, una condición inferior. Alfabetizar era una herramienta importante para el pasaje a una sociedad moderna, pues libertaría de la servidumbre para incluir al adulto en un orden social ya definido en la teoría del capital humano. La propuesta del DINEA-CREAR se diferenciaba por basarse en el pensamiento de Paulo Freire y en el liberalismo laico, donde predominaba una fuerte asociación entre política y educación. Los centros de alfabetización se tornaron centros de cultura. De una visión técnica y productiva la acción educativa pasaba a ser mirada como transformadora y formadora de conciencia, vinculando la propuesta política y educativa para la transformación social que concebía al adulto como un sujeto activo.

En el capítulo catorce El discurso escolar y las políticas editoriales de los libros de educación media (1960-2005), Tosi identifica dos momentos de las políticas editoriales de los libros de textos de educación media: Consolidación del modelo pedagógico de los años 1960 a 1982 y la Mercantilización pedagógica en los anos 1983 al 2005. La autora describe el contexto de enseñanza secundaria argentina desde el siglo XIX destacando la expansión de esta modalidad de enseñanza desde los años treinta al sesenta. Había un reducido número de libros didácticos y, en un Estado benefactor, con fuerte intervención en la economía y políticas sociales, la política editorial se instauró y conservó el saber escolar escrito, homogeneizando un saber considerado sólido y consensual. Los cambios pretendían eliminar el 
discurso peronista de los libros y construir un cánon pedagógico monolítico, el régimen de la dictadura represora transformó el modelo pedagógico, retirando algunos libros de circulación y editando otros con parámetros ideológicos que parecían inmutables. Después de 1983 se inició un período de mercantilización del libro, condicionado por el mercado, factores comerciales, oferta y demanda. El Estado delega a las empresas editoriales la producción y control de los contenidos, se eliminan las normas represivas, constituyendo un mercado de servicios educativos mediante oferta y demanda. Esto generó nuevos discursos de circulación de obras, que eran substituidas provocando productividad y rentabilidad, estableciendo una profunda modificación en el mercado editorial del país.

En el capítulo quince La enseñanza de las primeras letras en tiempos de dictadura, Mannochi aborda la lectura y la escritura en Buenos Aires en la última dictadura militar (1976-1983). Para analizar los contenidos epistemológicos, psicológicos y didácticos aplicados la autora recorre a los reglamentos y programas oficiales y entrevistas a docentes del período. A pesar de las investigaciones del área afirmar que en este período tuvo un vaciamiento de la enseñanza, subordinación de los maestros y de las consecuencias funestas del período dictatorial, afirma que es posible percibir experiencias significativas entre alumnos y profesores en el mismo período. $\mathrm{Al}$ confrontar las fuentes orales y los documentos oficiales en la historia de la educación argentina, resaltó los riesgos de la cronología que oculta las transformaciones educativas y muestra que no es posible establecer una simple continuidad sobre la política gubernamental y la práctica docente. El capítulo dieciséis Los saberes letrados en la sociedad de la información: lector, soportes y ritmos sociales, Rodríguez debate acerca de las relaciones complejas del papel de la tecnología digital, las consecuencias sociales de la lectura electrónica en el aprendizaje escolar y los cambios de modelos pedagógicos en la era de la Internet. Recurriendo a la corriente de la tecnología de la palabra evalúa las tecnologías de comunicación, destacando las críticas y otras corrientes de interpretación, apuntando a la superficialidad y la capacidad de atención. Destaca el papel de la escuela en asegurar a todos los bienes culturales fundamentales, acuerda que las tecnologías, mientras producen desconcierto y confusión mediante las excesivas informaciones, son parte de la vida cotidiana escolar. El autor resalta la función de la escuela en la democratización universal de los conocimientos y que la misma debe ser el centro de las políticas públicas, aprovechando las tecnologías para el aprendizaje de los saberes técnicos y teóricos, transformando así la sociedad de la información en la sociedad del pensamiento.

El último capítulo Un panorama de las teorías de la alfabetización en América Latina durante las últimas décadas (1980-2010) Castedo y Torres, a partir de una exploración bibliográfica, debaten acerca de las tres teorías más difundidas 
al respecto del aprendizaje de la escritura: Whole Language, Lenguaje Integral, modelo en que el foco de la lectura se alimenta progresivamente de las investigaciones sobre textos, procesos de escrituras, diversidades sociolingüísticas y alfabetización; Conciencia Fonológica que se interesa por el diagnóstico de la capacidad de aislar los fonemas considerados la clave del éxito del aprendizaje de la lectura e investigación psicogenética, en la cual el marco sociohistórico tiene un papel fundamental en la comprensión del proceso, y la escritura es un sistema de marcas sociales culturalmente construidas en que el niño necesita reconstruir. Las autoras concluyen que la relación lengua oral, lengua escrita, concepción de error, diversidad y variación lingüística son puntos coincidentes y discrepantes en el estudio. 